\title{
PRECIPITAÇÃO E TEMPERATURA DO AR PARA O ESTADO DE MATO GROSSO UTILIZANDO KRIGAGEM ORDINÁRIA
}

\author{
RAMOS, Henrique da Cruz - henriquecruzr@gmail.com \\ Universidade do Estado do Mato Grosso - UNEMAT \\ DALLACORT, Rivanildo - rivanildo@unemat.br \\ Universidade do Estado do Mato Grosso - UNEMAT
}

NEVES, Sandra Mara Alves da Silva - ssneves@unemat.br Universidade do Estado do Mato Grosso - UNEMAT

DALCHIAVON, Flavio Carlos - fcdalchiavon@hotmail.com Instituto Federal do Mato Grosso - IFMT

SANTI, Adalberto - adalbertosanti@unemat.br Universidade do Estado do Mato Grosso - UNEMAT

VIEIRA, Francielle Freitas - franciellefreitascosta@hotmail.com Universidade do Estado do Mato Grosso - UNEMAT

\begin{abstract}
RESUMO: O clima de uma região é determinante para as atividades econômicas nela desenvolvidas, bem como o tipo de vegetação predominante e tipo de solo. O presente trabalho objetivou espacializar as variáveis meteorológicas, tais como a precipitação e temperatura. Para tanto, foram utilizados dados de 38 estações meteorológicas e 21 postos pluviométricos distribuídos no estado de Mato Grosso e em estados limítrofes com no mínimo 12 anos de observações, tendo como método interpolador a krigagem ordinária para quatro modelos de semivariogramas. 0 regime pluviométrico apresentou duas estações bem definidas no estado, sendo uma seca, de maio a setembro e outra chuvosa, de março a outubro. O modelo exponencial foi o que apresentou melhor ajuste aos dados de precipitação no período chuvoso, no entanto, no período seco, o modelo gaussiano se adequou melhor para os dados de temperatura. Observou-se que a precipitação média anual no estado, variou entre 1.200 e $2.200 \mathrm{~mm}$, com os maiores valores ocorrendo no norte do estado. Quanto à temperatura do ar, a média anual variou entre 22 e $27,6{ }^{\circ} \mathrm{C}$, a máxima entre 28 e $33,3^{\circ} \mathrm{C}$ e as mínimas entre 16 e $20^{\circ} \mathrm{C}$, sendo as menores temperaturas presentes no sudeste do estado.
\end{abstract}

Palavras- chaves: Climatologia, variação espacial, semivariogramas.

\section{RAINFALL AND AIR TEMPERATURE FOR THE STATE OF MATO GROSSO USING ORDINARY KRIGING}

ABSTRACT: The climate of a region is critical for developed economic activities, as well as the predominant type of vegetation and soil type. This study aimed spatialize weather variables, such as precipitation and temperature. To this end, data from 38 meteorological stations and 21 rainfall stations distributed in the state of Mato Grosso and in neighboring states with at least 12 years of observations were used, with the interpolation method to ordinary kriging for four models of semivariogram. The rainfall presented two well-defined seasons in the state, with a dry, from May to September and a rainy season, from March to October. The exponential model showed the best fit to the data of rainfall in the rainy season, however, the dry season, the Gaussian model is better suited for the temperature data. It was observed that the average annual rainfall in the state varied between 1,200 and 2,200 mm, with the highest values occurring in the northern state. As the air temperature, the annual average was between 22 and 27.6 ${ }^{\circ} \mathrm{C}$, the maximum between 28 and $33.3^{\circ} \mathrm{C}$ and the minimum between 16 and $20^{\circ} \mathrm{C}$, with the lowest temperatures present in the southeastern state.

Keys- words: Climatology, spatial variation, semivariograms. 


\section{INTRODUÇÃO}

O clima de uma região é determinante no tipo de vegetação presente, tipo de solo da região, e em diversas atividades econômicas praticadas pelo homem, sendo a agricultura uma das mais afetadas. O clima influencia, por exemplo, no modelo de agricultura praticado, tais como, sequeiro, no qual toda água necessária ao cultivo é obtida via precipitação pluvial o que torna o modelo mais susceptível as variações climáticas, ou irrigado, no qual quando necessário é feita a suplementação de água via irrigação buscando atender à necessidade hídrica da cultura, o que diminui consideravelmente o risco de frustração da safra causada pelo déficit hídrico, uma vez que a precipitação pluvial é a característica climática de maior imprevisibilidade e variação espaço-temporal (BURIOL et al., 2007; BECKER et al., 2013). Desta forma, o estudo do clima torna-se essencial para diversos ramos da sociedade.

Para simplificar, organizar e generalizar as condições climáticas, segundo Bardin et al., (2010), o clima pode ser classificado utilizando apenas algumas variáveis chaves, neste contexto, a precipitação e a temperatura são as mais utilizadas, bem como a sazonalidade destas.

A temperatura do ar é, entre os elementos climáticos, o que mais interfere na fisiologia de plantas e animais, uma vez que a interferência ocorre de forma direta sobre estes seres. Assim, o conhecimento prévio desta variável atmosférica, é essencial para o planejamento agrícola e estudos de aptidão de cultivos e cultivares para diferentes regiões (STRECK et al., 2011).

O estudo da precipitação pluvial é de grande importância para o planejamento de atividades agrícolas, construção civil, turismo e transporte, sendo fundamental para a realização de trabalhos relacionados à conservação do solo, e construções de estradas e barragens (BEIJO et al.,2009).

Para a espacialização de variáveis meteorológicas, podem ser utilizados diversos métodos de interpolação, como o inverso ponderado da distância, spline, topo to raster, dentre outros, destacando-se entre estes, a krigagem, por se tratar de um método geoestatístico (MARCUZZO et al., 2011; ALVES e VECCHIA, 2011; GUARDIMAN JUNIOR et al., 2012).

A krigagem é um método interpolador, que tem por princípio a teoria das variáveis regionalizadas, onde o valor de uma variável possui uma dependência espacial, ou seja, parte do pressuposto que, valores das amostras próximas tendem a ser semelhantes, e valores de amostras distantes, tendem a ser mais discrepantes, considerando a variação espacial de determinada variável estatisticamente homogênea em uma área, sendo a variação espacial quantificada por um semivariograma experimental (MARCUZZO et al, 2011).

O Estado de Mato Grosso (Figura 1) possui uma área de $903.366,2$ km² inseridos em três biomas: Amazônia, Cerrado e Pantanal (SEDTUR, 2013). A principal atividade econômica do estado é a agropecuária, que em sua grande maioria é exercida em sistema de sequeiro, o que a torna totalmente vulnerável às variações climáticas (IBGE, 2012) 


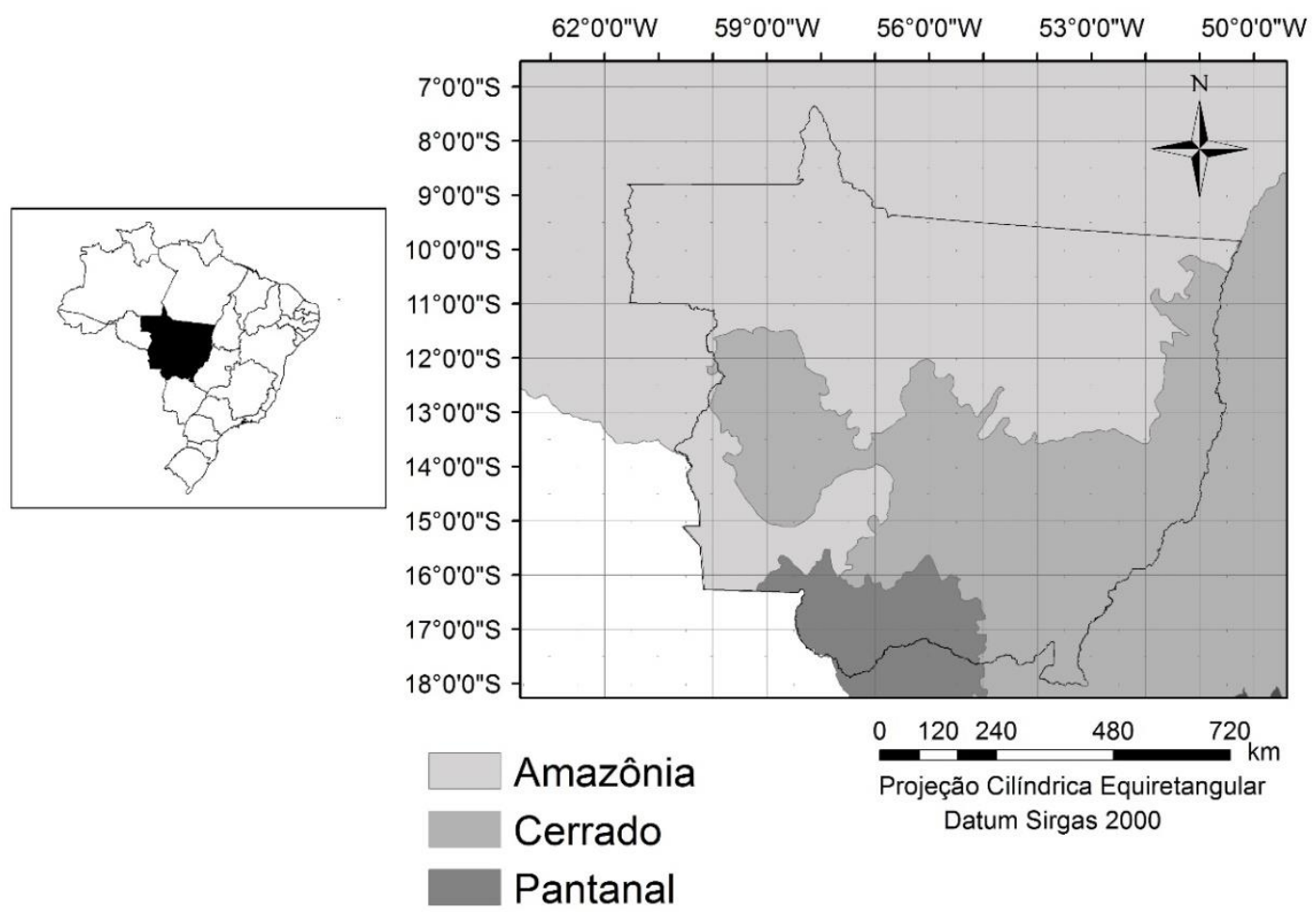

Figura 1 - Território do Estado de Mato Grosso e seus biomas.

Deste modo este trabalho tem por objetivo gerar cartas de precipitação, temperatura mínima, média e máxima por meio da interpolação dos dados por krigagem ordinária, em escalas mensal e anual, observando a variabilidade do espaço temporal das variáveis em estudo.

\section{MATERIAL E MÉTODOS}

Utilizou-se dados diários de precipitação pluviométrica, temperatura mínima média (Tmim), média (Tmed) e máxima média (Tmax) de 38 e estações meteorológicas, oriundas do site Agritempo $®$, que reúne estações do Instituto Nacional de Meteorologia (INMET), Centro de Previsão de Tempo e Estudos Climáticos (CPTEC), Secretária de Estado do Desenvolvimento Ambiental - RO (SEDAM) e mais 21 postos pluviométricos da Agência Nacional das Águas (ANA), obtidos junto ao site Hidroweb $\Re$, localizados no Estado de Mato Grosso e em estados limítrofes (Figura 2), com no mínimo 12 anos de observações, devido à baixa disponibilidade de séries de observações longas no estado.

Tabela 1 - Representação das Médias e Índices Sazonais de TMCM ( ${ }^{\circ} \mathrm{C}$ ) em Recife (1990-2009)

\begin{tabular}{lllllr}
\hline Fonte & Estação meteorológica & Período & Latitude & Longitude & Altitude $(\mathrm{m})$ \\
\hline INMET & Alta Floresta & $1979-2012$ & $10^{\circ} 40^{\prime} \mathrm{S}$ & $56^{\circ} 45^{\prime} \mathrm{W}$ & 294 \\
ANA & Alto Boa Vista & $1993-2012$ & $11^{\circ} 40^{\prime} \mathrm{S}$ & $51^{\circ} 22^{\prime} \mathrm{W}$ & 235 \\
ANA & Apiácas & $1993-2011$ & $08^{\circ} 52^{\prime} \mathrm{S}$ & $57^{\circ} 07^{\prime} \mathrm{W}$ & 212
\end{tabular}




\begin{tabular}{|c|c|c|c|c|c|}
\hline Fonte & Estação meteorológica & Período & Latitude & Longitude & Altitude $(\mathrm{m})$ \\
\hline INMET & Aripuanã & $1979-2012$ & $10^{\circ} 09^{\prime S}$ & $59^{\circ} 27^{\prime} W$ & 105 \\
\hline INMET & Ariquemes & $1982-2012$ & $09^{\circ} 55^{\prime} \mathrm{S}$ & $62^{\circ} 57^{\prime} \mathrm{W}$ & 119 \\
\hline ANA & Barra Do Bugres & 1974-2009 & $15^{\circ} 19^{\prime} \mathrm{S}$ & $57^{\circ} 13^{\prime} \mathrm{W}$ & 128 \\
\hline ANA & Brasnorte & $1985-2012$ & $11^{\circ} 43^{\prime} \mathrm{S}$ & $58^{\circ} 03^{\prime} \mathrm{W}$ & 257 \\
\hline INMET & Cáceres & $1962-2012$ & $16^{\circ} 03^{\prime} \mathrm{S}$ & $57^{\circ} 40^{\prime} \mathrm{W}$ & 118 \\
\hline INMET & Cacoal & $1978-2012$ & $11^{\circ} 29^{\prime} \mathrm{S}$ & $61^{\circ} 22^{\prime} \mathrm{W}$ & 186 \\
\hline INMET & Caiapônia & $1978-2012$ & $16^{\circ} 58^{\prime} \mathrm{S}$ & $51^{\circ} 49^{\prime} \mathrm{W}$ & 737 \\
\hline INMET & Campo Verde & 1977-2012 & $16^{\circ} 18^{\prime} \mathrm{S}$ & $55^{\circ} 04^{\prime} \mathrm{W}$ & 749 \\
\hline INMET & Canarana & $1996-2010$ & $13^{\circ} 30^{\prime} \mathrm{S}$ & $52^{\circ} 30^{\prime} \mathrm{W}$ & 430 \\
\hline INMET & Canarana & $2000-2012$ & $13^{\circ} 28^{\prime} \mathrm{S}$ & $52^{\circ} 16^{\prime} \mathrm{W}$ & 430 \\
\hline INMET & Chapadão do Sul & $1983-2012$ & $18^{\circ} 00^{\prime} \mathrm{S}$ & $52^{\circ} 36^{\prime} \mathrm{W}$ & 818 \\
\hline ANA & Cocalinho & $1985-2012$ & $14^{\circ} 05^{\prime} \mathrm{S}$ & $51^{\circ} 42^{\prime} \mathrm{W}$ & 232 \\
\hline ANA & Colíder & 1994-2012 & $10^{\circ} 48^{\prime} \mathrm{S}$ & $55^{\circ} 27^{\prime} \mathrm{W}$ & 313 \\
\hline ANA & Comodoro & 1994-2012 & $13^{\circ} 10^{\prime} \mathrm{S}$ & $59^{\circ} 52^{\prime} \mathrm{W}$ & 600 \\
\hline INMET & Comodoro & $1971-2012$ & $13^{\circ} 25^{\prime} \mathrm{S}$ & $59^{\circ} 27^{\prime} \mathrm{W}$ & 591 \\
\hline INMET & Conceição do Araguaia & $1962-2012$ & $8^{\circ} 16^{\prime} S$ & $49^{\circ} 16^{\prime} \mathrm{W}$ & 156 \\
\hline INMET & Corumbá & $1962-2012$ & $19^{\circ} 01^{\prime} \mathrm{S}$ & $57^{\circ} 39^{\prime} \mathrm{W}$ & 130 \\
\hline INMET & Cuiabá & $1961-2010$ & $15^{\circ} 37^{\prime} \mathrm{S}$ & $56^{\circ} 06^{\prime} \mathrm{W}$ & 145 \\
\hline INMET & Cuiabá & $1962-2012$ & $15^{\circ} 37^{\prime} \mathrm{S}$ & $56^{\circ} 06^{\prime} \mathrm{W}$ & 145 \\
\hline INMET & Cuiabá & $1968-2012$ & $15^{\circ} 33^{\prime} S$ & $56^{\circ} 04^{\prime} \mathrm{W}$ & 245 \\
\hline CPTEC & Cuiabá & $1968-2012$ & $15^{\circ} 37^{\prime} \mathrm{S}$ & $56^{\circ} 06^{\prime} \mathrm{W}$ & 151 \\
\hline INMET & Diamantino & $1961-2010$ & $14^{\circ} 24^{\prime} S$ & $56^{\circ} 27^{\prime} \mathrm{W}$ & 286 \\
\hline SEDAM & Diamantino & $1965-2012$ & $12^{\circ} 17^{\prime} \mathrm{S}$ & $55^{\circ} 17^{\prime} \mathrm{W}$ & 415 \\
\hline ANA & General Carneiro & $1992-2012$ & $15^{\circ} 42^{\prime} \mathrm{S}$ & $52^{\circ} 45^{\prime} \mathrm{W}$ & 366 \\
\hline INMET & Gleba Celeste & $1973-2010$ & $12^{\circ} 12^{\prime} \mathrm{S}$ & $56^{\circ} 30^{\prime} \mathrm{W}$ & 415 \\
\hline INMET & Humaitá & $1980-2102$ & $07^{\circ} 30^{\prime} \mathrm{S}$ & $63^{\circ} 01^{\prime} \mathrm{W}$ & 61 \\
\hline ANA & Indiavaí & 1993-2012 & $15^{\circ} 26^{\prime} \mathrm{S}$ & $58^{\circ} 35^{\prime} \mathrm{W}$ & 235 \\
\hline INMET & Jatai & $1978-2012$ & $17^{\circ} 52^{\prime} \mathrm{S}$ & $52^{\circ} 35^{\prime} \mathrm{W}$ & 663 \\
\hline INMET & Juara & $1979-2012$ & $11^{\circ} 22^{\prime} \mathrm{S}$ & $57^{\circ} 31^{\prime} \mathrm{W}$ & 260 \\
\hline INMET & Juína & $1979-2012$ & $11^{\circ} 22^{\prime} \mathrm{S}$ & $58^{\circ} 46^{\prime} \mathrm{W}$ & 374 \\
\hline ANA & Luciara & $1986-2012$ & $11^{\circ} 13^{\prime} \mathrm{S}$ & $50^{\circ} 40^{\prime} \mathrm{W}$ & 182 \\
\hline INMET & Matupá & $1987-2010$ & $10^{\circ} 15^{\prime} \mathrm{S}$ & $54^{\circ} 55^{\prime} \mathrm{W}$ & 285 \\
\hline INMET & Mineiros & $1974-2012$ & $17^{\circ} 52^{\prime} \mathrm{S}$ & $52^{\circ} 35^{\prime} \mathrm{W}$ & 706 \\
\hline ANA & Mirassol D'Oeste & $1993-2012$ & $15^{\circ} 28^{\prime} \mathrm{S}$ & $57^{\circ} 53^{\prime} \mathrm{W}$ & 188 \\
\hline INMET & Nova Xavantina & $1988-2010$ & $14^{\circ} 42^{\prime} \mathrm{S}$ & $52^{\circ} 21^{\prime} \mathrm{W}$ & 316 \\
\hline ANA & Novo Santo Antônio & $1992-2012$ & $12^{\circ} 17^{\prime} \mathrm{S}$ & $50^{\circ} 58^{\prime} \mathrm{W}$ & 205 \\
\hline INMET & Padre Ricardo Remetter & $1987-2010$ & $15^{\circ} 47^{\prime} \mathrm{S}$ & $56^{\circ} 04^{\prime} \mathrm{W}$ & 140 \\
\hline ANA & Paranatinga & $1983-2011$ & $13^{\circ} 27^{\prime} S$ & $54^{\circ} 16^{\prime} \mathrm{W}$ & 430 \\
\hline CPTEC & Paranatinga & $1977-2012$ & $14^{\circ} 25^{\prime} S$ & $54^{\circ} 02^{\prime} \mathrm{W}$ & 474 \\
\hline ANA & Pontes e Lacerda & $1975-2012$ & $15^{\circ} 13^{\prime} \mathrm{S}$ & $59^{\circ} 21^{\prime} \mathrm{W}$ & 236 \\
\hline ANA & Porto Alegre do Norte & $1993-2012$ & $10^{\circ} 52^{\prime} \mathrm{S}$ & $51^{\circ} 37^{\prime} W$ & 202 \\
\hline
\end{tabular}




\begin{tabular}{lllllr}
\hline Fonte & Estação meteorológica & Período & Latitude & Longitude & Altitude (m) \\
INMET & Porto dos Gaúchos & $1983-2012$ & $11^{\circ} 32^{\prime} \mathrm{S}$ & $57^{\circ} 25^{\prime} \mathrm{W}$ & 274 \\
ANA & Porto Esperidião & $1993-2012$ & $15^{\circ} 51^{\prime} \mathrm{S}$ & $58^{\circ} 28^{\prime} \mathrm{W}$ & 166 \\
INMET & Poxoréo & $1977-2010$ & $15^{\circ} 50^{\prime} \mathrm{S}$ & $54^{\circ} 23^{\prime} \mathrm{W}$ & 450 \\
ANA & Ribeirão Cascalheira & $1992-2011$ & $12^{\circ} 56^{\prime} \mathrm{S}$ & $51^{\circ} 49^{\prime} \mathrm{W}$ & 391 \\
ANA & Rio Branco & $1993-2012$ & $15^{\circ} 15^{\prime} \mathrm{S}$ & $58^{\circ} 06^{\prime} \mathrm{W}$ & 124 \\
INMET & Rondonópolis & $1995-2010$ & $16^{\circ} 27^{\prime} \mathrm{S}$ & $54^{\circ} 34^{\prime} \mathrm{W}$ & 284 \\
INMET & Rondonópolis & $1966-2012$ & $16^{\circ} 27^{\prime} \mathrm{S}$ & $54^{\circ} 33^{\prime} \mathrm{W}$ & 284 \\
INMET & Rondonópolis & $1966-2012$ & $15^{\circ} 46^{\prime} \mathrm{S}$ & $56^{\circ} 04^{\prime} \mathrm{W}$ & 140 \\
INMET & Sto Antônio do Leverger & $2000-2012$ & $16^{\circ} 27^{\prime} \mathrm{S}$ & $54^{\circ} 28^{\prime} \mathrm{W}$ & 284 \\
INMET & São Felix do Araguaia & $1977-2012$ & $11^{\circ} 37^{\prime} \mathrm{S}$ & $50^{\circ} 43^{\prime} \mathrm{W}$ & 218 \\
INMET & São Jose do Rio Claro & $1996-2010$ & $13^{\circ} 26^{\prime} \mathrm{S}$ & $56^{\circ} 43^{\prime} \mathrm{W}$ & 350 \\
ANA & São Jose do Xingu & $1990-2011$ & $10^{\circ} 48^{\prime S} \mathrm{~S}$ & $52^{\circ} 45^{\prime} \mathrm{W}$ & 337 \\
INMET & São Vicente & $1998-2010$ & $15^{\circ} 49^{\prime} \mathrm{S}$ & $55^{\circ} 25^{\prime} \mathrm{W}$ & 800 \\
ANA & Tabaporã & $1983-2012$ & $11^{\circ} 28^{\prime} \mathrm{S}$ & $56^{\circ} 25^{\prime} \mathrm{W}$ & 346 \\
ANA & Tangará da Serra & $1993-2012$ & $14^{\circ} 51^{\prime} \mathrm{S}$ & $57^{\circ} 46^{\prime} \mathrm{W}$ & 212 \\
ANA & Vila Rica & $1992-2012$ & $10^{\circ} 01^{\prime} \mathrm{S}$ & $51^{\circ} 07^{\prime} \mathrm{W}$ & 222 \\
\hline
\end{tabular}

A Figura 4 exibe a linha de tendência positiva para o período estudado em Para o preenchimento de falhas e análise de consistência, foi empregado o software CLIMA (Faria et al., 2003) desenvolvido pelo Instituto Agronômico do Paraná (IAPAR).

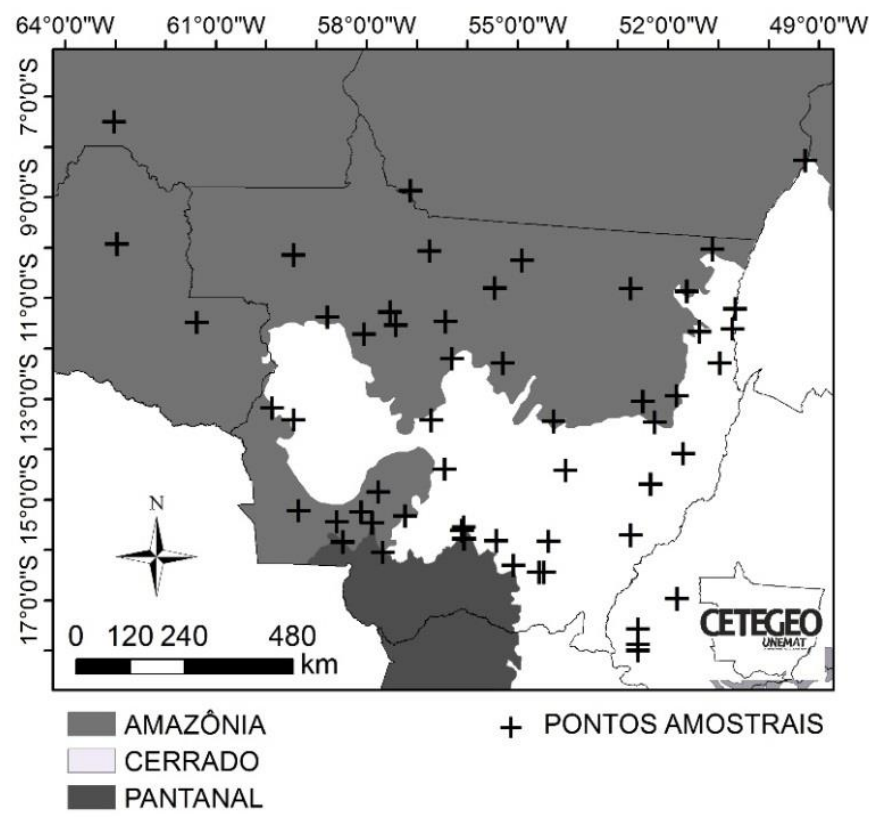

Figura 2 - Distribuição espacial das estações meteorológicas e postos pluviométricos utilizados. 
Os valores obtidos, foram espacializados utilizando 0 módulo Geostatistical Analyst do software ArcGis, versão 10, da ESRI. O método interpolador adotado foi a krigagem ordinária, utilizando quatro modelos de semivariogramas (exponencial, esférico, circular e gaussiano), que foram ajustados pelo software através de técnicas de validação cruzada, sendo escolhido o modelo que apresentou melhor precisão, ou seja, menor valor de raiz quadrada do erro quadrático médio (RMSE) (equação 1), como utilizado por Soares, et al. (2008) e Xavier et al. (2010).

$$
R M S E=\sqrt{\frac{\sum_{i=l}^{n}(\hat{Z}-z)^{2}}{n}}
$$

Onde:

RMSE: raiz quadrada do erro quadrático médio;

(Z ) ^ : valor estimado para um ponto conhecido;

z: valor real do ponto; e

$\mathrm{n}$ : número de observações.

O grau de dependência espacial (GD), que mede o quanto a variação dos dados podem ser explicados pela variação espacial, ou seja quanto dependem da variação espacial, foi calculado pela razão entre a variância estrutural (C) e o patamar $(\mathrm{CO}+\mathrm{C})$, de acordo com a equação 2, e avaliado de acordo com a classificação sugerida por Dalchiavon (2010) e utilizada por Dalchiavon e Carvalho (2012), sendo considerado muito baixo quando GD < 20\%; baixo quando $20 \% \leq \mathrm{GD}<40 \%$; médio quando $40 \% \leq \mathrm{GD}<60 \%$; alto quando $60 \%$ $\leq \mathrm{GD}<80 \%$ e a muito alto quando $80 \% \leq \mathrm{GD}<100 \%$.

$$
G D=\frac{C}{\left(C_{0}+C\right)}
$$

Onde:

GD: grau de dependência espacial;

C: é a variância estrutural;

C_0 : é o efeito pepita; e

C_0+C: é o patamar.

Após a interpolação dos dados e seleção do melhor modelo, foram confeccionadas as cartas climáticas. Para as cartas de precipitação, foi determinada uma amplitude de classe de $50 \mathrm{~mm}$ para o período chuvoso e 25 $\mathrm{mm}$ para o período de seca, já para as cartas de temperatura máxima, média e mínima, a amplitude foi de $1^{\circ} \mathrm{C}$.

\section{RESULTADOS E DISCUSSÃO}

O modelo de semivariograma que apresentou menor valor de RMSE para a variável precipitação, na estação das chuvas (outubro a abril) foi o modelo exponencial. Segundo Xavier et al. (2010) e Alves e Vecchia (2011), quanto mais próximo de zero os valores de RMSE mais precisa será a estimativa feita pelo modelo (Tabela 2). O alcance que mede a distância, em que, as amostras possuem correlação espacial variou entre 210,26 e $1.326 \mathrm{~km}$ para os diferentes meses sendo os valores mais altos observados no período chuvoso. 
Tabela 2 - Parâmetros dos semivariogramas para precipitação do Estado de Mato grosso

\begin{tabular}{ccccccc}
\hline Mês & Modelo & RMSE & $\mathrm{C}_{0}$ & Alcance $(\mathrm{km})$ & $\mathrm{C}_{0}+\mathrm{C}_{1}$ & $\mathrm{GD}(\%)$ \\
\hline Jan & Exponencial & 29,40 & 438,27 & 595,86 & $2.151,44$ & 79,63 \\
Fev & Exponencial & 36,22 & 67,49 & 682,58 & $3.095,74$ & 97,82 \\
Mar & Exponencial & 28,38 & 181,33 & 362,06 & $2.115,34$ & 91,43 \\
Abr & Circular & 21,69 & 66,63 & 916,22 & $1.842,12$ & 96,38 \\
Mai & Gaussiano & 17,29 & 206,79 & $1.296,58$ & $1.039,02$ & 80,10 \\
Jun & Gaussiano & 14,37 & 0,45 & $1.326,27$ & 1,67 & 72,99 \\
Jul & Gaussiano & 13,88 & 0,60 & $1.326,27$ & 1,70 & 64,89 \\
Ago & Gaussiano & 11,05 & 104,48 & $1.267,56$ & 261,43 & 60,04 \\
Set & Circular & 14,47 & 120,74 & 793,81 & 447,64 & 73,03 \\
Out & Exponencial & 22,04 & 154,64 & 210,26 & 737,34 & 79,03 \\
Nov & Gaussiano & 22,34 & 146,58 & 117,58 & $1.091,81$ & 86,57 \\
Dez & Circular & 30,51 & 201,91 & 101,87 & 908,86 & 77,78 \\
\hline Ano & Gaussiano & 145,87 & $6.852,37$ & 123,03 & $31.267,66$ & 78,08 \\
\hline
\end{tabular}

Estes resultados corroboram com os obtidos por Mello et al. (2008), que estudando a distribuição de precipitação pluvial, em Minas Gerais, onde foram modelados semivariogramas pelos modelos esférico, exponencial e gaussiano, sendo que o modelo exponencial foi superior aos demais em $75 \%$ das situações analisadas. Do mesmo modo, Carvalho et al. (2004) observaram, em estudo da precipitação pluvial, média anual para o Estado de São Paulo, que o modelo exponencial ajustou-se melhor aos semivariogramas, do que os modelos esférico e gaussiano.

O emprego do modelo exponencial para o mapeamento da precipitação pluviométrica, na estação chuvosa, encontrou forte estrutura de dependência espacial, evidenciado pelos baixos valores de RMSE, sendo este o modelo mais indicado para estudos ligados à distribuição das chuvas (ÁVILA et al., 2009).

No período seco (maio a setembro) o melhor modelo de ajuste foi o gaussiano, o que pode ser explicado pela grande variação da precipitação ocorrente neste período, mas mostrando nítida continuidade espacial do atributo estudado, efeito destacado por Mousinho et al. (2006) em estudo de variabilidade espacial de precipitação anual no Estado de Piauí.

Observou-se para a precipitação, que a dependência espacial foi maior nos meses da estação chuvosa, indicando que no período seco a precipitação tem caráter local. Para as variáveis Tmed e Tmax este efeito também se repetiu, segundo Varejão-Silva (2006) a umidade do ar influencia no comportamento da temperatura, pois a água atua como termorreguladora. O GD é considerado muito alto para os meses de novembro, fevereiro e março, e alto para os meses de outubro, dezembro e janeiro. Na estação seca o GD é considerado alto para todos os meses, exceto para maio que é considerado muito alto, por ser um mês de transição entre os períodos chuvoso e seco.

Para a temperatura mínima, os valores de RMSE apresentaram baixa amplitude, permanecendo próximos de zero, conferindo maior qualidade dos valores calculados (XAVIER et al., 2010; ALVES e VECCHIA, 2011). Os modelos que apresentaram melhor ajuste dos semivariogramas foram o gaussiano e o circular. Nota-se que o RMSE para a variável temperatura, apresentou variação 
anual de 1,05 (temperatura mínima) a 1,47 (temperatura máxima) (Tabelas 3, 4 e 5). Diferentemente do ocorrido com a precipitação pluviométrica, o modelo exponencial não obteve o melhor ajuste em nenhuma das variáveis de temperatura e meses do ano.

De maneira geral, observa-se que o GD para a temperatura mínima apresentou grande oscilação entre os meses do ano, variando de baixo, em dezembro $(33,71 \%)$ a alto, em janeiro, fevereiro, maio, julho e agosto, apresentando valores de $72,82 \%, 78,21 \%, 72,82 \%, 72,80 \%$ e $67,87 \%$, respectivamente.

Tabela 3 - Parâmetros dos semivariogramas para temperatura mínima do Estado de Mato Grosso.

\begin{tabular}{ccccccc}
\hline Mês & Modelo & RMSE & $\mathrm{C}_{0}$ & Alcance $(\mathrm{km})$ & $\mathrm{C}_{0}+\mathrm{C}_{1}$ & $\mathrm{GD}$ \\
\hline Jan & Gaussiano & 0,92 & 0,56 & 106,427 & 2,06 & 72,82 \\
Fev & Gaussiano & 0,85 & 0,41 & 106,43 & 1,90 & 78,21 \\
Mar & Circular & 0,96 & 0,98 & 404,22 & 1,95 & 49,88 \\
Abr & Circular & 1,12 & 1,31 & 404,22 & 2,63 & 51,32 \\
Mai & Esférico & 1,13 & 0,77 & 358,03 & 2,83 & 72,82 \\
Jun & Circular & 1,29 & 1,10 & 266,40 & 2,70 & 59,46 \\
Jul & Circular & 1,25 & 0,71 & 262,40 & 2,52 & 72,80 \\
Ago & Circular & 1,29 & 1,01 & 266,40 & 3,13 & 67,87 \\
Set & Gaussiano & 1,36 & 1,81 & 296,21 & 3,79 & 47,83 \\
Out & Gaussiano & 1,46 & 2,20 & 319,55 & 4,00 & 55,00 \\
Nov & Esférico & 1,23 & 1,40 & 319,55 & 2,87 & 49,01 \\
Dez & Gaussiano & 1,05 & 0,76 & 106,43 & 2,24 & 33,71 \\
\hline Ano & Gaussiano & 1,05 & 1,12 & 319,55 & 2,48 & 45,16 \\
\hline
\end{tabular}

$\mathrm{C}_{0}$ : efeito pepita; $\mathrm{C}_{0}+\mathrm{C}_{1}$ : patamar; GD: grau de dependência espacial.

Tabela 4 - Parâmetros dos semivariogramas para temperatura média do Estado de Mato Grosso

\begin{tabular}{ccccccc}
\hline Mês & Modelo & RMSE & $\mathrm{C}_{0}$ & Alcance $(\mathrm{km})$ & $\mathrm{C}_{0}+\mathrm{C}_{1}$ & $\mathrm{GD}$ \\
\hline Jan & Gaussiano & 0,81 & 0,23 & 111,82 & 2,34 & 90,03 \\
Fev & Gaussiano & 0,88 & 0,15 & 117,04 & 1,89 & 92,28 \\
Mar & Gaussiano & 0,99 & 0,39 & 117,04 & 1,93 & 80,00 \\
Abr & Circular & 1,22 & 1,20 & 331,72 & 2,46 & 51,18 \\
Mai & Esférico & 1,32 & 0,81 & 523,50 & 3,38 & 76,15 \\
Jun & Circular & 1,34 & 1,26 & 246,59 & 2,82 & 55,25 \\
Jul & Circular & 1,44 & 1,04 & 264,06 & 2,92 & 64,37 \\
Ago & Circular & 1,54 & 2,09 & 523,50 & 4,07 & 48,71 \\
Set & Gaussiano & 1,66 & 1,97 & 331,72 & 3,24 & 39,18 \\
Out & Circular & 1,37 & 0,73 & 111,82 & 2,40 & 69,74 \\
Nov & Gaussiano & 1,07 & 0,73 & 111,82 & 2,38 & 69,50 \\
Dez & Gaussiano & 0,87 & 0,31 & 111,82 & 2,49 & 87,45 \\
\hline Ano & Gaussiano & 1,21 & 1,19 & 190,41 & 2,24 & 46,78 \\
\hline
\end{tabular}

$\mathrm{C}_{0}$ : efeito pepita; $\mathrm{C}_{0}+\mathrm{C}_{1}$ : patamar; GD: grau de dependência espacial.

Observa-se, que os valores de RMSE para temperatura média, assim como os verificados para temperatura mínima do ar, também foram menores nos modelos gaussiano e circular para a maioria dos meses do ano, indicandoos, como melhores modelos de ajuste. Do mesmo modo, o modelo gaussiano apresentou melhor ajuste em todos os meses do ano para os valores de temperatura máxima, apresentando valores de RMSE variando de 0,91 em fevereiro a 2,45 em agosto. 
Tabela 5 - Parâmetros dos semivariogramas para temperatura máxima do Estado de Mato Grosso.

\begin{tabular}{ccccccc}
\hline Mês & Modelo & RMSE & $\mathrm{C}_{0}$ & Alcance $(\mathrm{km})$ & $\mathrm{C}_{0}+\mathrm{C}_{1}$ & $\mathrm{GD}$ \\
\hline Jan & Gaussiano & 0,97 & 0,38 & 117,31 & 2,67 & 85,59 \\
Fev & Gaussiano & 0,90 & 0,24 & 117,31 & 2,71 & 91,20 \\
Mar & Gaussiano & 1,05 & 0,64 & 117,31 & 2,78 & 77,04 \\
Abr & Gaussiano & 1,43 & 1,47 & 106,25 & 3,64 & 59,48 \\
Mai & Gaussiano & 1,58 & 2,10 & 189,54 & 4,22 & 50,17 \\
Jun & Gaussiano & 2,11 & 3,55 & 207,68 & 6,58 & 46,00 \\
Jul & Gaussiano & 2,17 & 3,58 & 214,10 & 6,92 & 48,31 \\
Ago & Gaussiano & 2,45 & 5,48 & 207,68 & 8,69 & 36,93 \\
Set & Gaussiano & 2,27 & 4,96 & 207,68 & 7,62 & 34,91 \\
Out & Gaussiano & 1,76 & 3,18 & 318,14 & 4,61 & 30,91 \\
Nov & Gaussiano & 1,34 & 1,17 & 106,25 & 3,87 & 69,75 \\
Dez & Gaussiano & 1,31 & 1,15 & 64,27 & 3,15 & 63,59 \\
\hline Ano & Gaussiano & 1,47 & 2,03 & 189,54 & 3,41 & 40,64 \\
\hline
\end{tabular}

$\mathrm{C}_{0}$ : efeito pepita; $\mathrm{C}_{0}+\mathrm{C}_{1}$ : patamar; GD: grau de dependência espacial.

De acordo com os valores de GD para os modelos ajustados, observa-se Que a temperatura média e temperatura máxima, apresentaram em alguns meses, grau de dependência espacial baixo, dificultando 0 ajuste do semivariograma (MELLO et al., 2008).

A precipitação anual do estado (Figura 3) variou entre 1.200 e $2.200 \mathrm{~mm}$ com os valores decrescendo no sentido norte sul, corroborando com os resultados observados por Moraes et al. (2005) para o estado do Pará, cuja precipitação anual média ficou entre 1.800 e $2.300 \mathrm{~mm}$ na região sul do estado, que faz divisas com Mato Grosso.

Através da variação temporal da precipitação, verificou-se, a ocorrência de duas estações no estado de Mato Grosso, uma chuvosa, de outubro a abril, e outra seca, de maio a setembro, estes resultados estão de acordo com estudos realizados por Dallacort et al. (2010), Moreira et al. (2010), Martins et al. (2011), Dallacort et al. (2011) e Pizzato et al. (2012), bem como o esperado em toda a região central do Brasil (GAN e MOSCATI, 2003), onde, estudando o regime pluviométrico de alguns municípios do estado de Mato Grosso, esses autores também verificaram a existência de duas estações bem definidas, sendo uma seca e outra chuvosa.. 


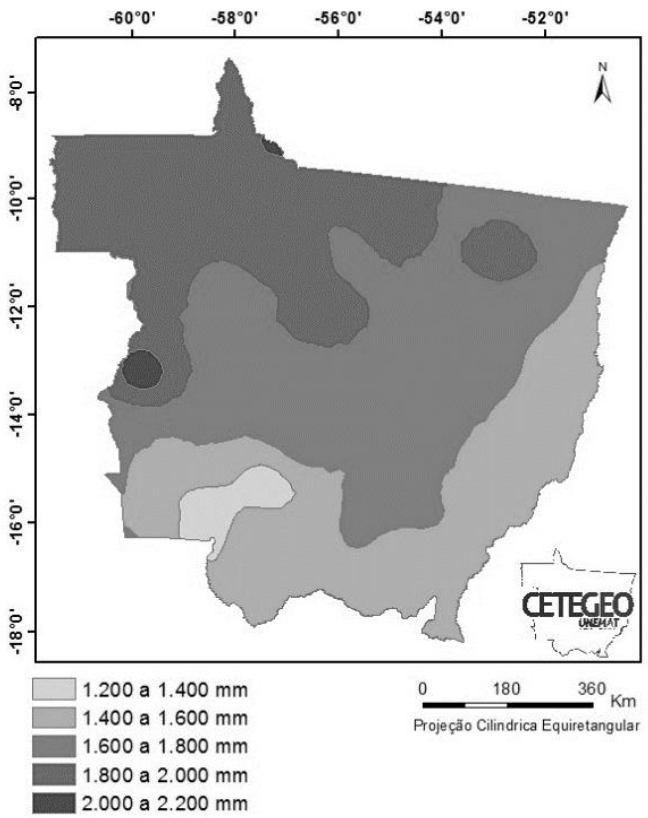

Figura 3 - Precipitação $(\mathrm{mm})$ anual para o Estado de Mato Grosso.

Observa-se que no início da estação chuvosa, que compreende o mês de outubro, as precipitações se concentram ao norte do estado, progredindo para o sul com o passar dos meses (Figura 4), pois a maior parte das precipitações que ocorrem na região neste período do ano são resultantes das massas de ar quente e úmido formadas na Amazônia, que, com o avançar da estação chuvosa ficam mais fortes e avançam mais ao sul do continente gradativamente (MOLION, 1987).

Do mesmo modo com o fim do período chuvoso (Figura 5), segundo Gan e Moscati (2003), estas massas de ar quente e úmido vão perdendo força indo cada vez menos a sul. Sem estas massas, a precipitação no sul da Amazônia e o Cerrado mato-grossense ficam dependentes das frentes frias e úmidas oriundas do polo sul, que devido a distância e continentalidade do estado não chegam com tanta intensidade quanto as quentes. O que resulta em uma média mensal baixa e, que em alguns anos, pode chegar a zero nos meses de junho, julho e agosto.

Na região do pantanal (Figuras 4 e 5), há uma maior distribuição da precipitação durante o ano. Apesar de esta região possuir as menores somas pluviométricas anuais do estado, este fato pode estar relacionado à grande umidade ali presente, ocasionando chuvas do tipo convectivas, durante o período de seca.

Nota-se, grande disparidade no total precipitado na região do Cerrado (centro e leste do estado), quando comparadas as estações chuvosa e seca. Segundo Assad et al. (1993) a estação chuvosa pode ser responsável por até $90 \%$ do total precipitado durante o ano neste bioma. 

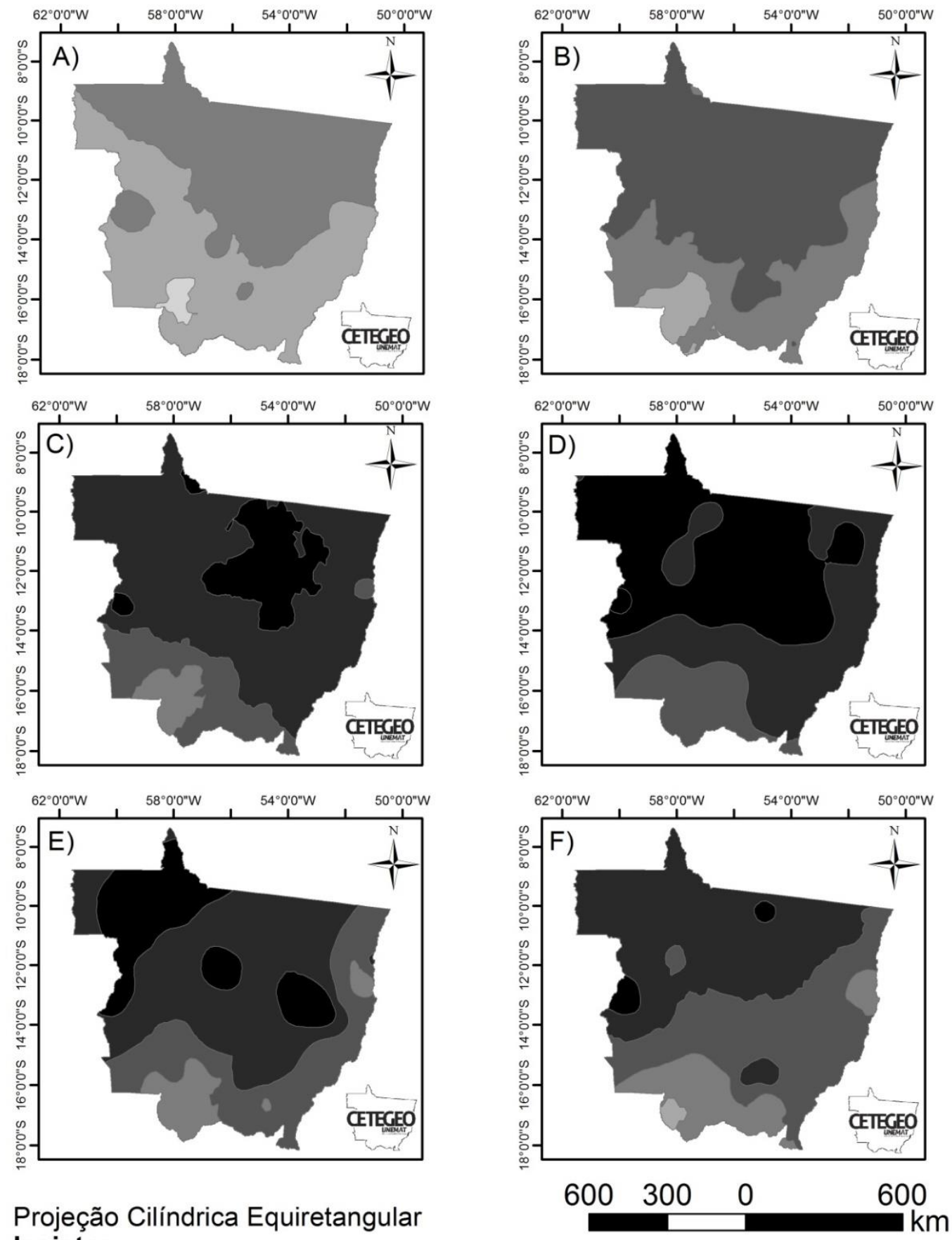

Projeção Cilíndrica Equiretangular

\section{Isoietas}

\begin{tabular}{ll}
\hline 0 a $50 \mathrm{~mm}$ & 150,1 a $200 \mathrm{~mm}$ \\
\hline 50,1 a $100 \mathrm{~mm}$ & 200,1 a $250 \mathrm{~mm}$ \\
100,1 a $150 \mathrm{~mm}$ & 250,1 a $300 \mathrm{~mm}$
\end{tabular}

Figura 4 - Precipitação pluvial nos meses de outubro (A), novembro (B), dezembro (C), janeiro (D), fevereiro (E) e março (F) para o Estado de Mato Grosso. 

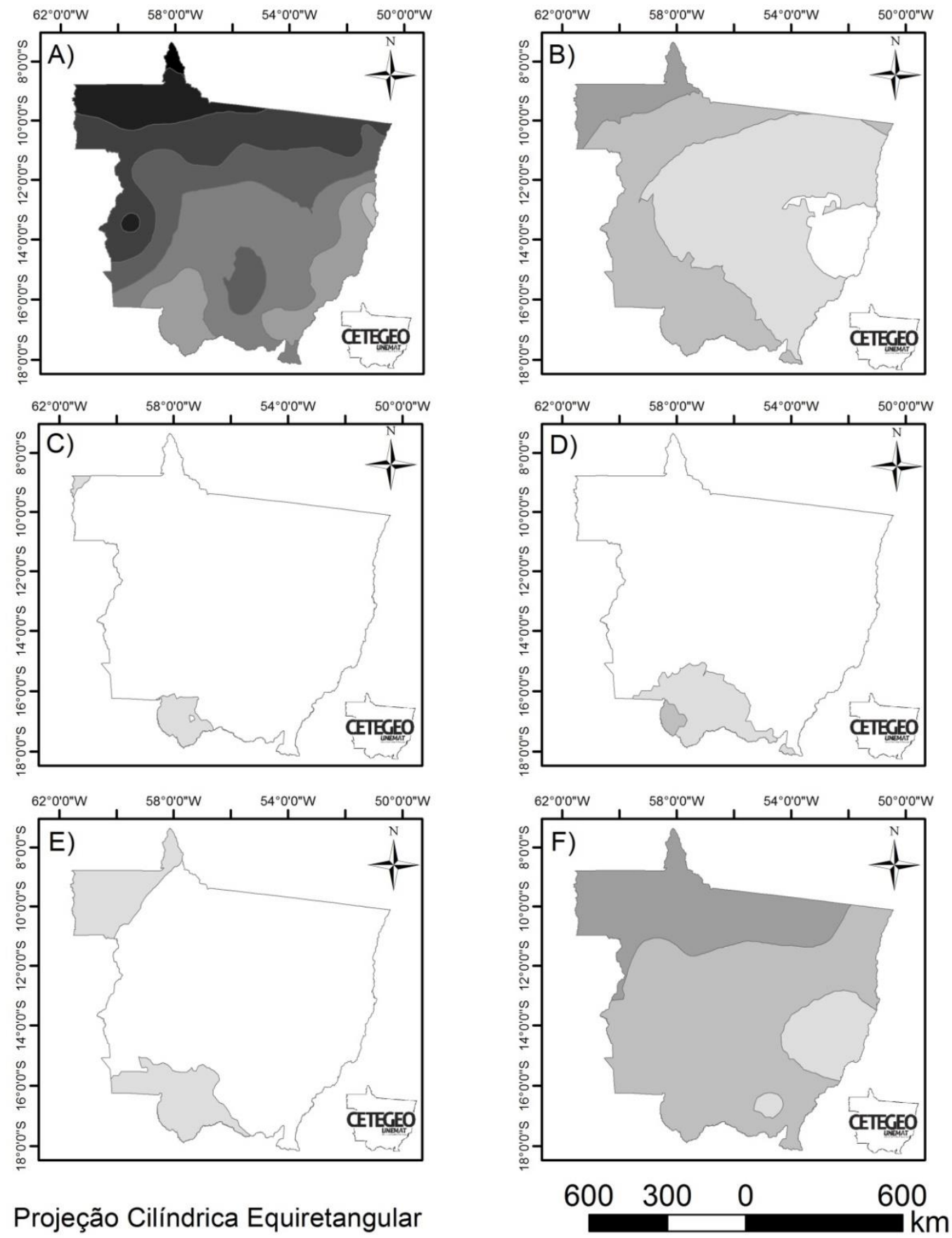

Projeção Cilíndrica Equiretangular

\section{Isoietas}

$\square \quad 0$ a $25 \mathrm{~mm}$
$\square \quad 25$ a $50 \mathrm{~mm}$
50 a $75 \mathrm{~mm}$

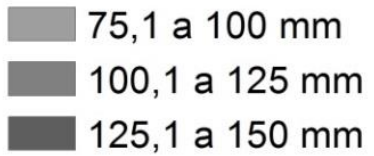

150,1 a $175 \mathrm{~mm}$

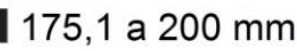

200,1 a $225 \mathrm{~mm}$

Figura 5 - Precipitação pluvial nos meses de abril (A), maio (B), junho (C), julho (D), agosto (E) e setembro (F) para o Estado de Mato Grosso. 
A Tmax anual (Figura 6) ficou entre 28,30 e $33,30{ }^{\circ} \mathrm{C}$, sendo que as maiores temperaturas encontram-se no nordeste do estado. A Tmed anual variou entre 22,39 e $26,56^{\circ} \mathrm{C}$ (Figura 7). Entretanto, observa-se que boa parte do território $(69,77 \%)$ apresentou Tmed de 24,47 e $25,52{ }^{\circ} \mathrm{C}$. A média anual da Tmim (Figura 8) é de 16,03 e 20,18, porém 62,39\% da área do estado estão no intervalo de 18,11 a $19,15^{\circ} \mathrm{C}$. Garcia et al. (2013), verificaram comportamento próximo aos resultados descrito acima, para a região de Sinop - MT, com 30 anos de dados de observações.

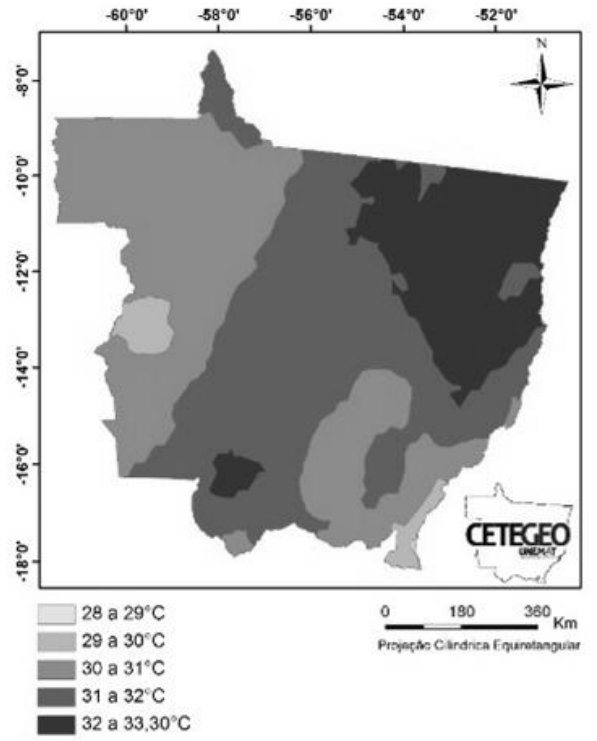

Figura 6 - Temperatura máxima média do ar anual para o Estado de Mato Grosso.

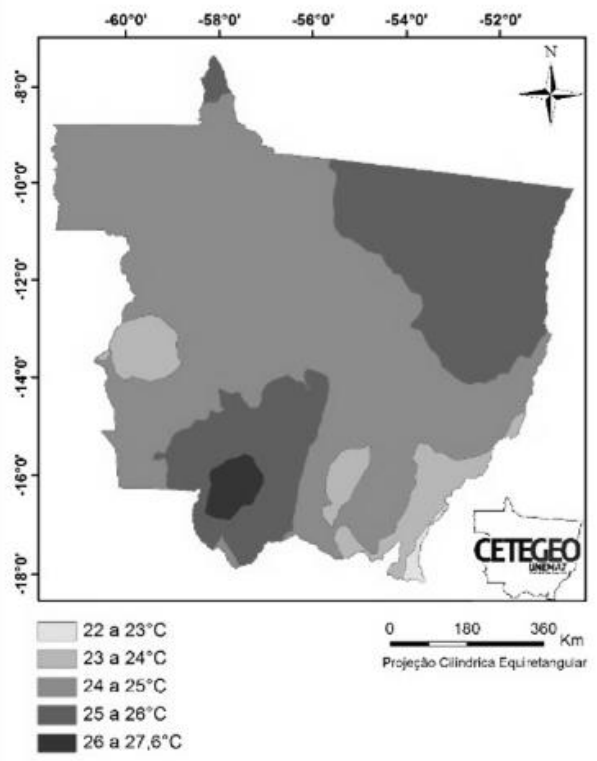

Figura 7 - Temperatura média do ar anual para o Estado de Mato Grosso. 


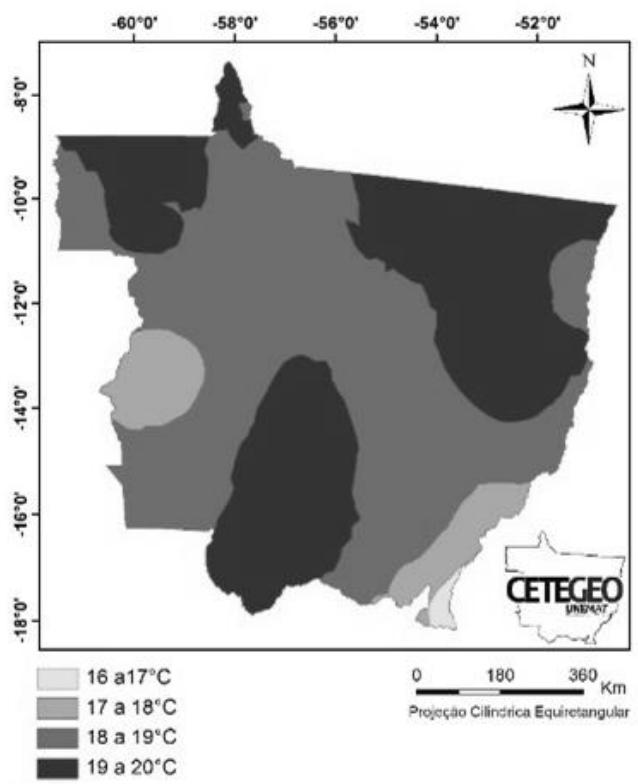

Figura 8 - Temperatura mínima média do ar anual para o Estado de Mato Grosso.

No período chuvoso as temperaturas máximas (Figura 9) variaram entre 28,2 e $34^{\circ} \mathrm{C}$, sendo que as maiores máximas foram observadas no mês de outubro. Para este mesmo período, as temperaturas médias do ar (Figura 10) variam de 23 a $27,88{ }^{\circ} \mathrm{C}$, sendo o mês de novembro correspondente aos maiores valores. Quanto à temperatura mínima (Figura 11), houve variação entre 17 e 23,54 ${ }^{\circ} \mathrm{C}$, apresentando os menores valores em outubro. Resultados obtidos por Vilani et al. (2006) em estudo sobre sazonalidade das variáveis climáticas em uma floresta de transição no Estado de Mato Grosso, estão de acordo com o presente estudo, com resultados de temperatura média do ar de $25,5^{\circ} \mathrm{C}$ a $27,8^{\circ} \mathrm{C}$.

$\mathrm{Na}$ estação seca as temperaturas máximas (Figura 12) foram maiores que as observadas no período chuvoso, variando entre 26 e $35,8{ }^{\circ} \mathrm{C}$, apresentando uma maior amplitude. As temperaturas médias (Figura 13), variou entre 19 e $27^{\circ} \mathrm{C}$. As temperaturas mínimas (Figura 14), apresentaram menores valores, com média mensal de $17^{\circ} \mathrm{C}$ e não mais que $21^{\circ} \mathrm{C}$. Observa-se ainda que as menores temperaturas ocorreram no sul do estado o que pode ser explicado pelo efeito latitudinal. 

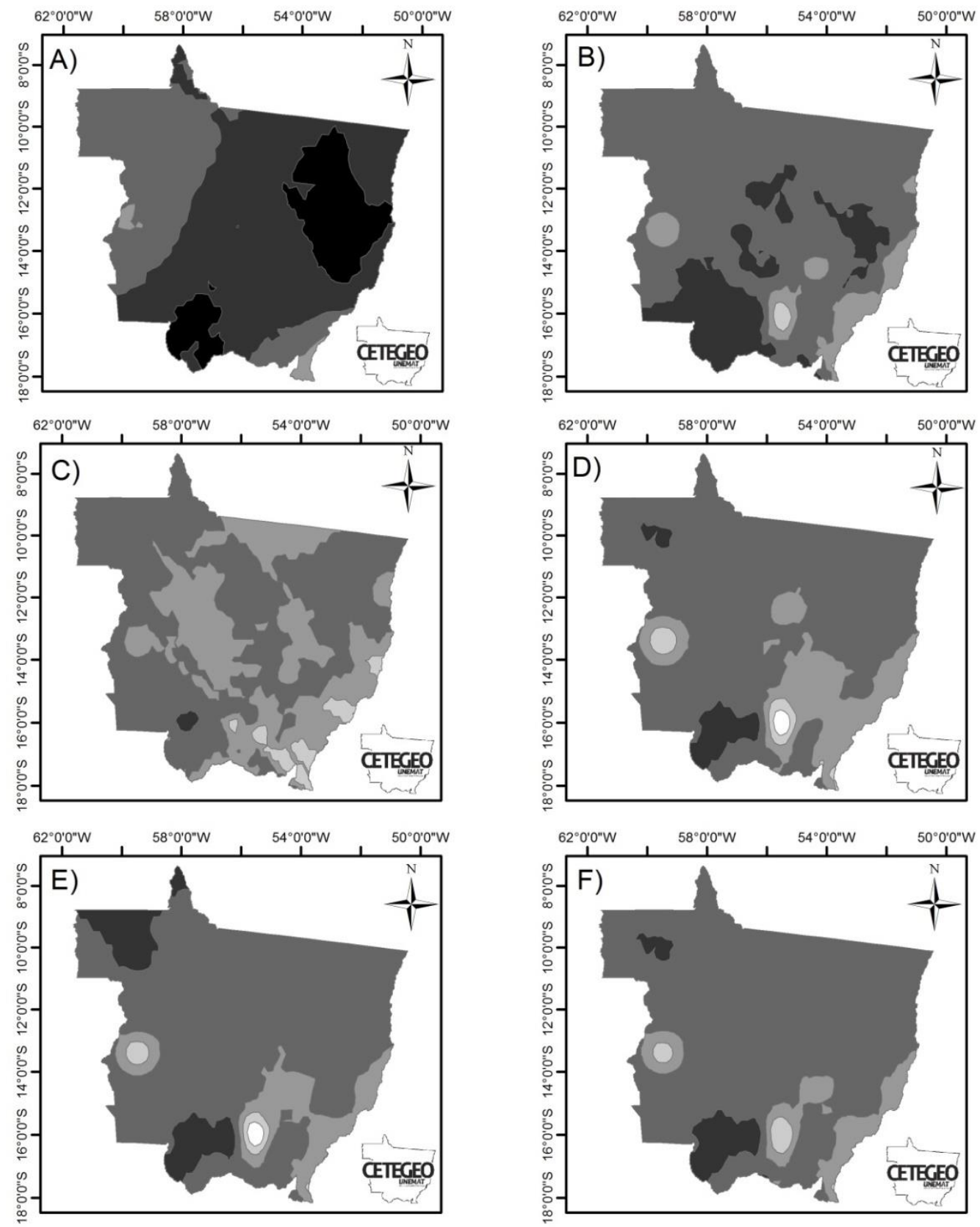

Projeção Cilíndrica Equiretangular

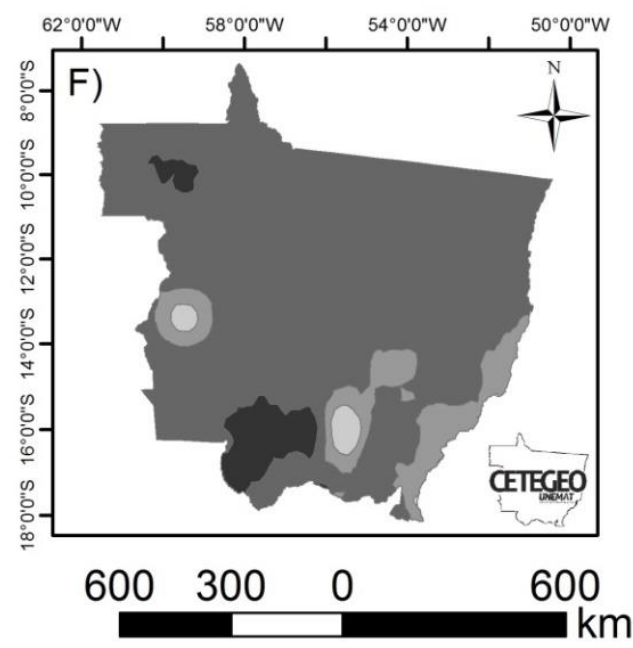

\section{Isotermas}

$\square 28,1$ a $29^{\circ} \mathrm{C}$

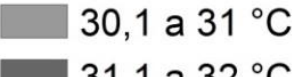

32,1 a $33^{\circ} \mathrm{C}$
33,1 a $34^{\circ} \mathrm{C}$

Figura 9 - Temperatura máxima média nos meses de outubro $(A)$, novembro $(B)$, dezembro (C), janeiro (D), fevereiro (E) e março (F). 

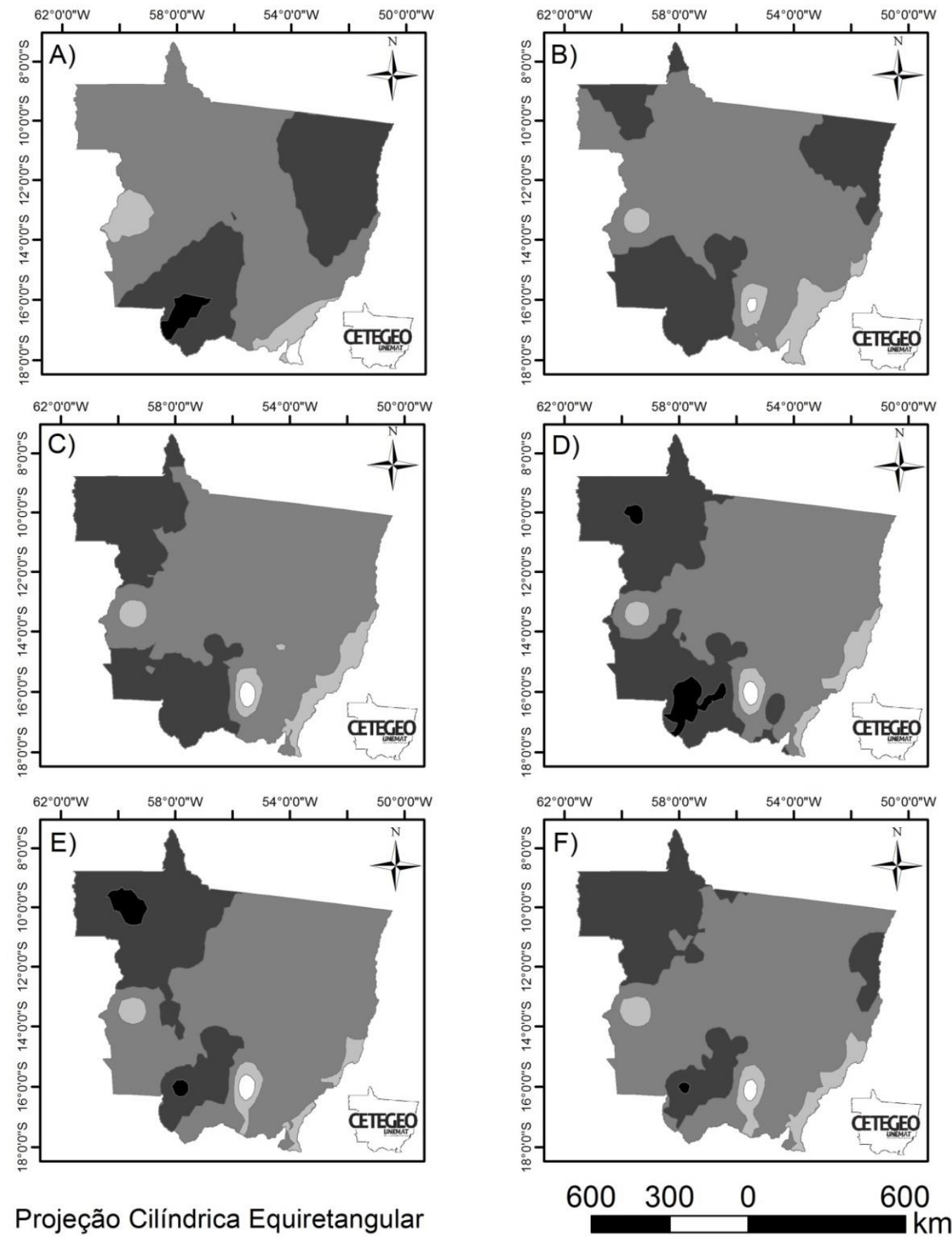

Projeção Cilíndrica Equiretangular

\section{Isotermas}

$\square 23,1$ a $24^{\circ} \mathrm{C}$

25,1 a $26{ }^{\circ} \mathrm{C}$

27,1 a $28^{\circ} \mathrm{C}$

Figura 10 - Temperatura média nos meses de outubro (A), novembro (B), dezembro $(C)$, janeiro (D), fevereiro $(E)$ e março $(F)$. 

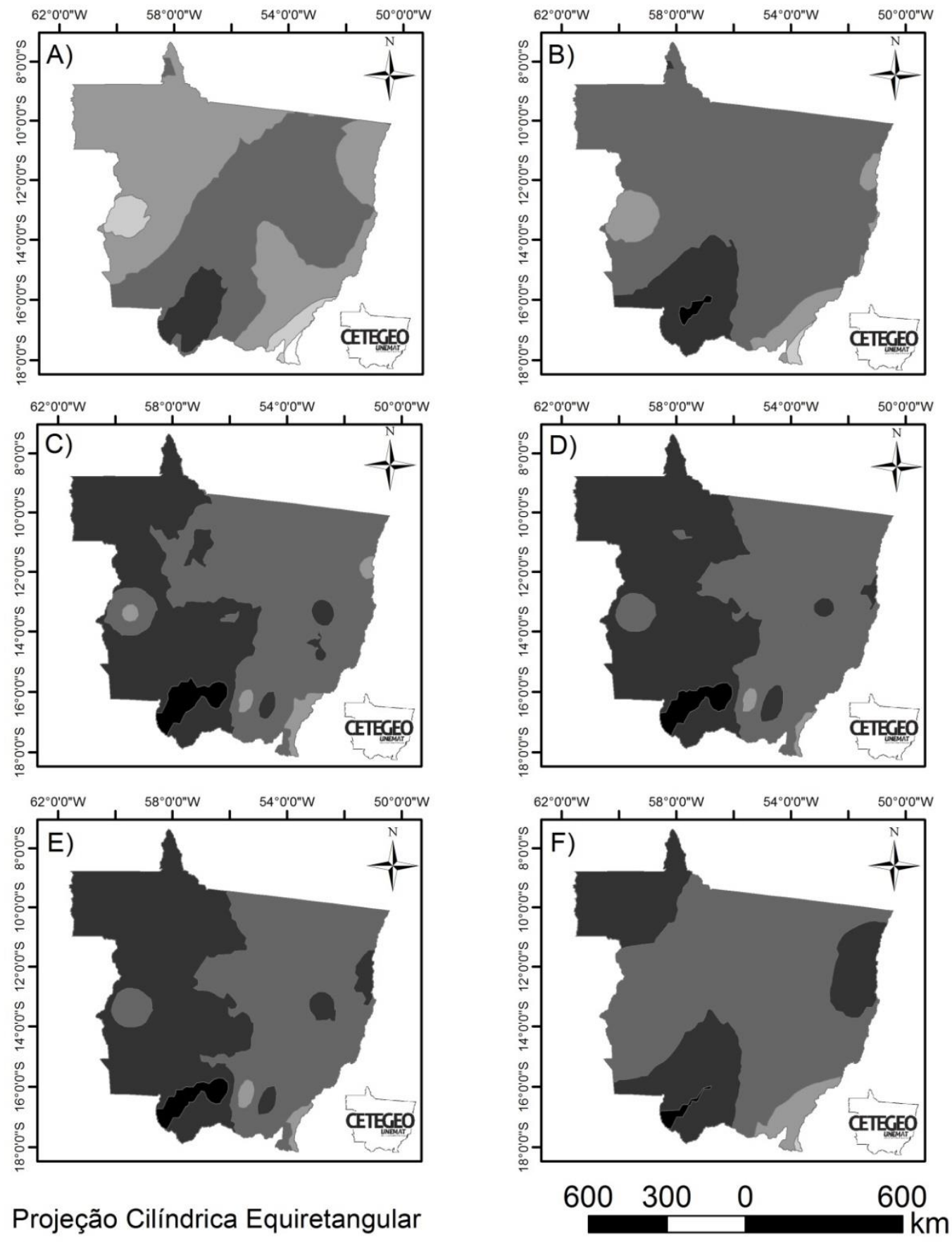

Projeção Cilíndrica Equiretangular Isotermas

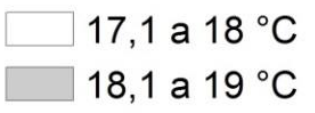

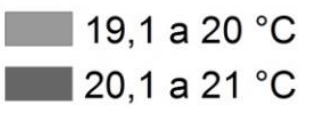

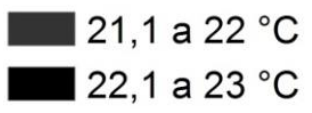

Figura 11 - Temperatura mínima média nos meses de outubro (A), novembro (B), dezembro (C), janeiro (D), fevereiro (E) e março (F). 

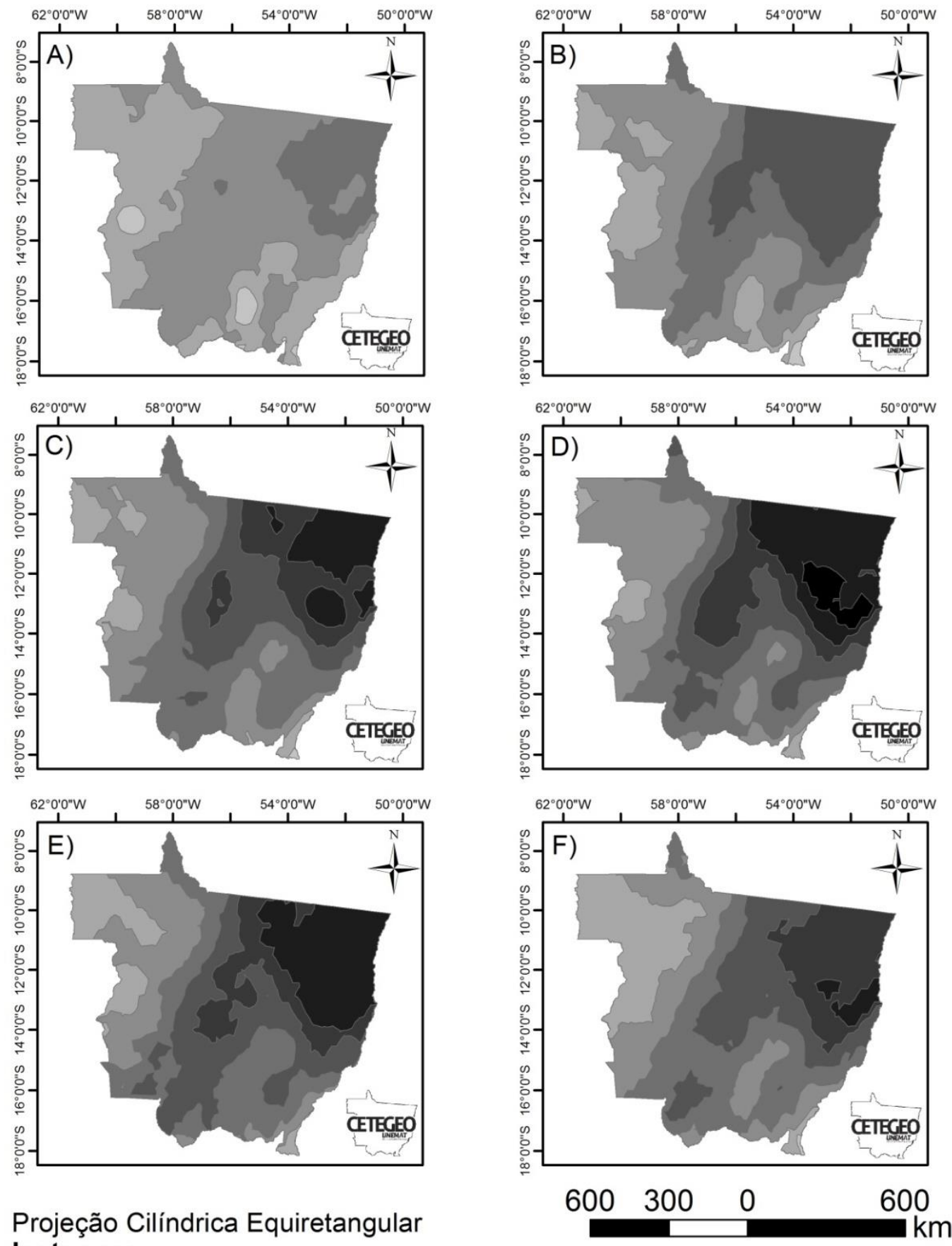

\section{Projeção Cilíndrica Equiretangular} Isotermas

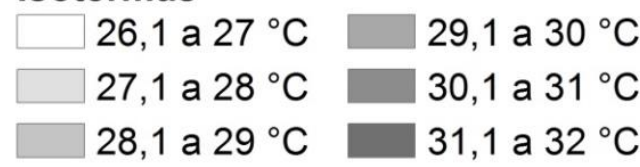

32,1 a $33^{\circ} \mathrm{C} \square 35,1$ a $36{ }^{\circ} \mathrm{C}$

33,1 a $34^{\circ} \mathrm{C}$

34,1 a $35^{\circ} \mathrm{C}$

Figura 12 - Temperatura máxima média do ar nos meses de abril (A), maio (B), junho $(C)$, julho (D), agosto (E) e setembro (F). 

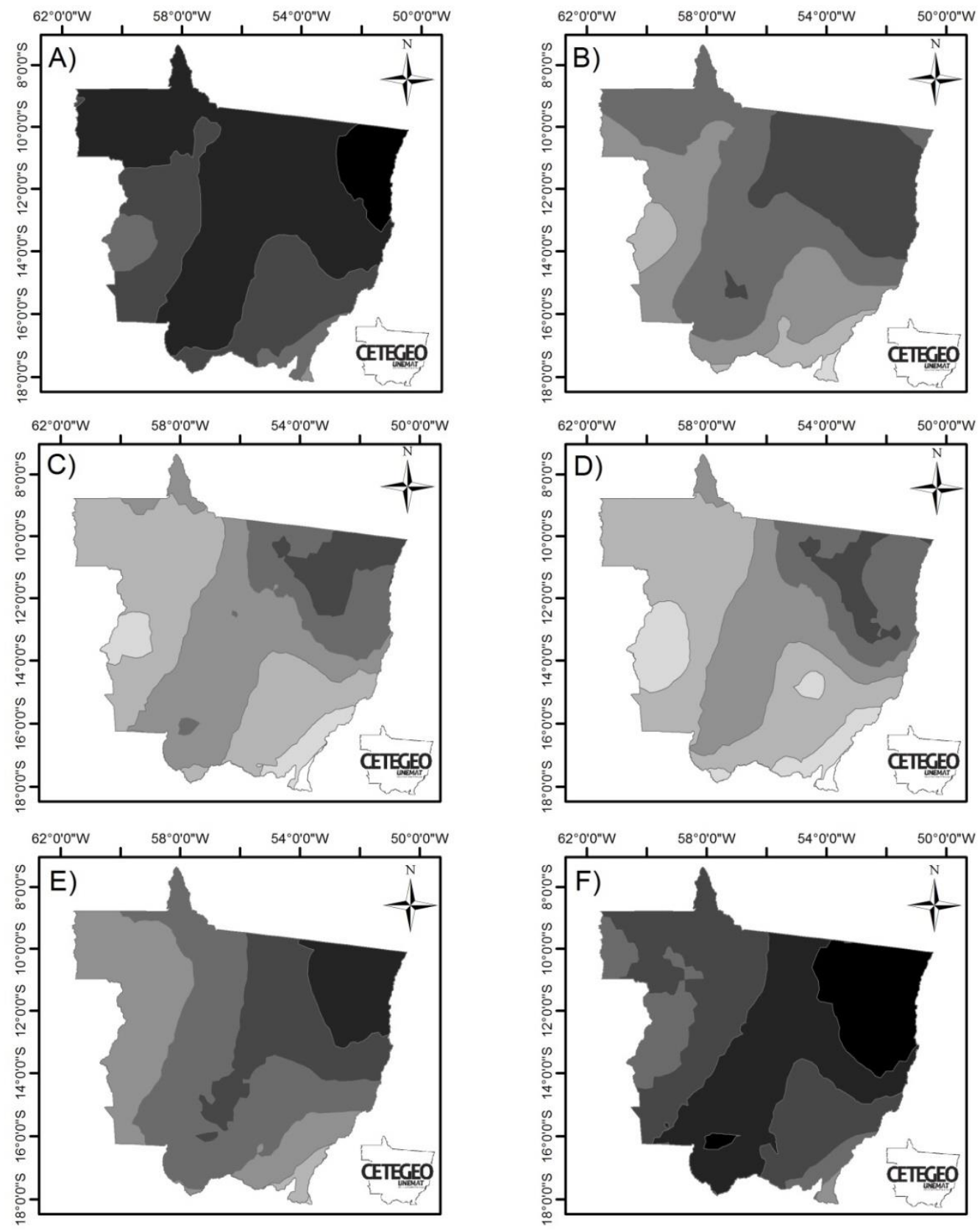

Projeção Cilíndrica Equiretangular

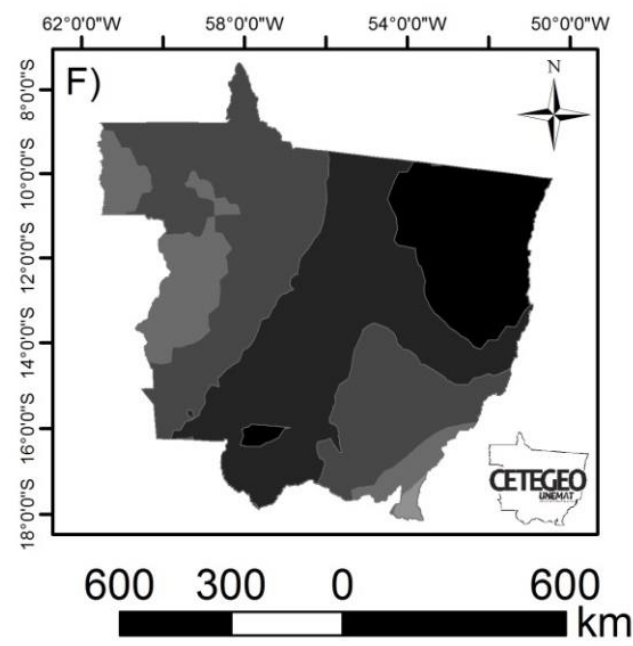

\section{Isotermas}

20,1 a $21^{\circ} \mathrm{C}$

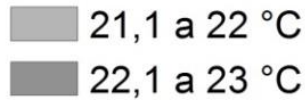

23,1 a $24{ }^{\circ} \mathrm{C}$

25,1 a $26{ }^{\circ} \mathrm{C}$

24,1 a $25^{\circ} \mathrm{C}$

26,1 a $27^{\circ} \mathrm{C}$

Figura 13 - Temperatura média do ar nos meses de abril (A), maio (B), junho (C), julho (D), agosto (E) e setembro (F). 

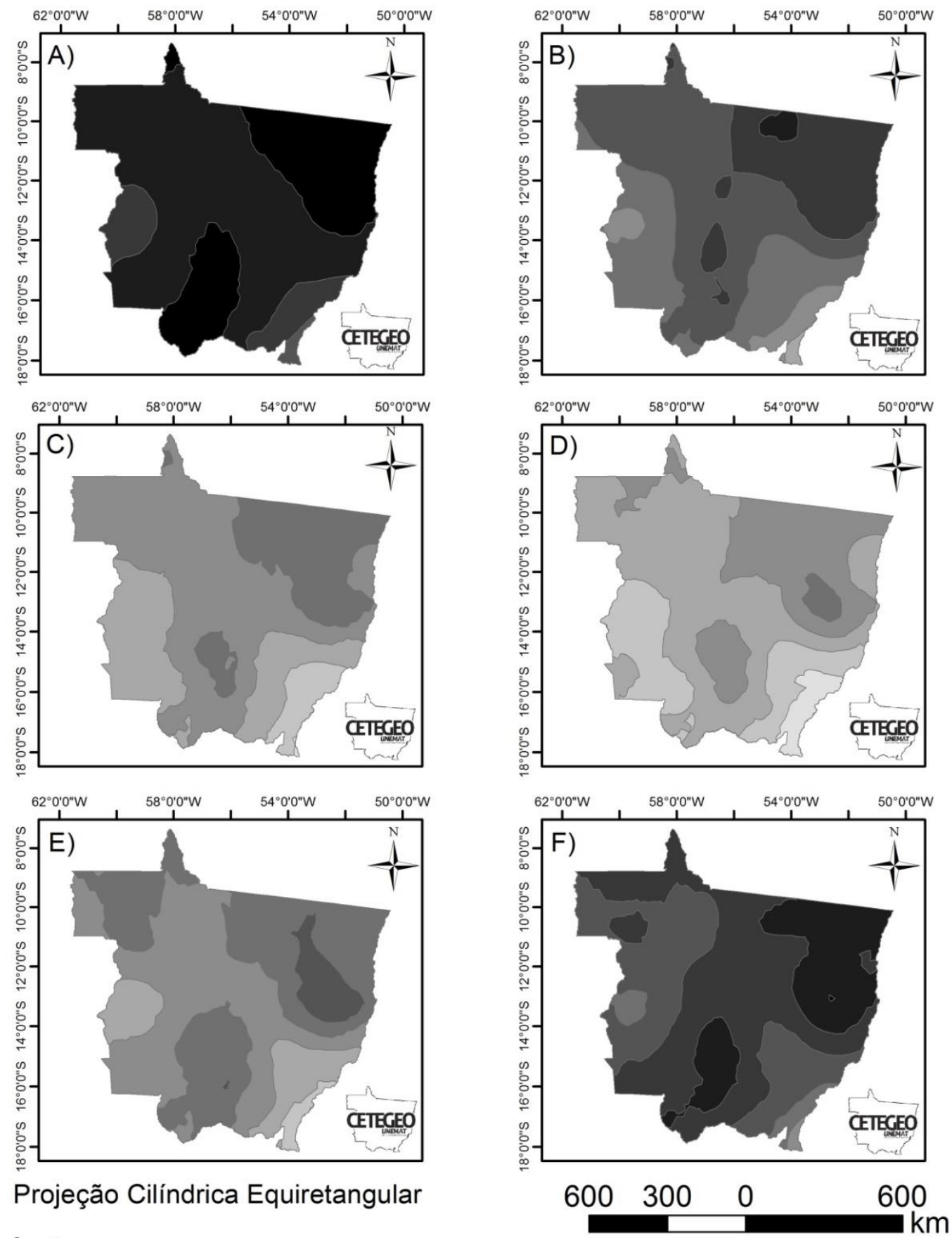

\section{Isotermas}

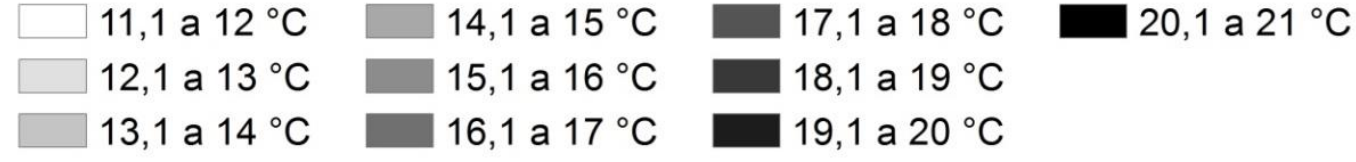

Figura 14 - Temperatura mínima média do ar nos meses de abril (A), maio (B), junho $(C)$, julho (D), agosto (E) e setembro (F). 
O ar atmosférico sempre contém quantidade variável de vapor de água $A$ partir da análise dos resultados obtidos neste trabalho, foi possível observar que a precipitação do Estado de Mato Grosso está diretamente relacionada às frentes equatoriais provenientes da Amazônia, responsáveis pelas precipitações no período chuvoso. Deste modo, o norte do estado apresenta as maiores médias pluviométricas durante o ano, apresentando um período chuvoso mais longo que o restante do estado.

Todavia, na estação seca, as chuvas passam a ser dependentes das frentes frias provenientes do polo sul, e as maiores precipitações passam a ocorrer no sul do estado, sendo que neste período as precipitações apresentam maior variabilidade espacial, uma vez que chegam com menor intensidade ao estado, tornando as precipitações mais dependentes de fatores microclimáticos.

Quanto à temperatura, observa-se que esta é fortemente influenciada pelo efeito latitudinal, com as maiores temperaturas médias, ocorrendo na região do Cerrado e durante o período chuvoso, este período apresenta as menores máximas e as maiores mínimas, indicando menor amplitude térmica. Contudo, o período seco é marcado pelas maiores máximas e menores mínimas, bem como maiores variações espaciais para as três temperaturas, as máximas, médias e mínimas, reduzindo a qualidade das interpolações realizadas.

\section{CONCLUSÕES}

O Estado de Mato Grosso apresenta duas estações bem definidas, sendo uma seca, de maio a setembro e outra chuvosa, de março a outubro.

O modelo exponencial apresentou melhor ajuste aos dados de precipitação no período chuvoso, para o período seco, o modelo gaussiano foi melhor.

A precipitação média anual no estado, variou entre 1.200 e 2.200 mm, com os maiores valores ocorrendo no norte do estado.

A temperatura do ar, a média anual variou entre 22 e $27,6^{\circ} \mathrm{C}$, a máxima entre 28 e $33,3^{\circ} \mathrm{C}$ e as mínimas entre 16 e $20{ }^{\circ} \mathrm{C}$, sendo as menores temperaturas presentes no sudeste do estado.

Há diferenciação do clima nos três biomas, na Amazônia, altas temperaturas combinadas com altos índices pluviométricos, no centro leste do estado, onde se localiza o Cerrado, duas estações bem definidas, uma chuvosa e outra seca, e o Pantanal com índice pluviométrico baixo e uma estação chuvosa mais tardia quando comparado ao restante do estado

\section{REFERÊNCIAS BIBLIOGRÁFICAS}

ALVES, J. M. B.; SOUZA, R. O.; CAMPOS, J. N. B. Previsão da anomalia de temperatura da superfície do mar (tsm) no atlântico tropical, com a equação da difusão de temperatura. Revista Climanalise, ano 03, n. 01, 2005.

BERTALANFFY, Ludwig Von. Teoria General de los Sistemas, 10a ed., México: FCE, 1995.

BLOCH, S. C. EXCEL para Engenheiros e Cientistas. Rio de Janeiro: LTC, 2004. 
BOX, G E P. Time Series Analysis: Forecasting and Control. 3. ed. Englewood Cliffs: Prentice Hall, 1994. 598p.

BELTRÃO, N. E. M.; ARAúJO, A E; BENASSI, A C; Zoneamento e época de plantio para o algodoeiro no norte do Espírito Santo. Revista Brasileira de Engenharia Agrícola e Ambiental, Campina Grande, v.7, n.1, p.99-105, 2003.

BEZERRA, A. C.; CAVALCANTI, E. P. Energia estática sobre o Nordeste do Brasil relacionada com a temperatura da superfície do mar. Revista Brasileira de Meteorologia, São José dos Campos, v. 23, n. 2, p. 239-263, 2008.

COSTA, E V. Medidas da Umidade relativa do Ar em um ambiente fechado. Revista Brasileira de Ensino de Física, vol. 25, no. 3, Setembro, 2003.

DELGADO, R. C.; SEDIYAMA, G. C.; ANDRADE, R G. Modelos para prognósticos da umidade relativa do ar em escala horária no município de Muriaé, MG. Anais I Seminário de Recursos Hídricos da Bacia Hidrográfica do Paraíba do Sul: o Eucalipto e o Ciclo Hidrológico, Taubaté, Brasil, 07-09 novembro 2007, IPABHi, p. 295-300.

DIGGLE P. J. Time series: a biostatistical introduction. Oxford: Oxford University Press, 1992.

FILHO, R. A. P., SILVA, J. C. C., Gomes, S. B. Sistemas Integrados de Tratamento e usos de Águas Residuárias na América Latina: Realidade e Potencial. 54 p, Centro Pan-Americano de Engenharia Sanitária e Ciências do Ambiente. Fortaleza. 2002.

HASTENRATH, S. Interannual Variability and Annual Cycle: Mechanisms of Circulation and Climate in the Tropical Atlantic Sector. Mon. Wea. Rev., 112, 1097-1107. 1984.

KOUSKY,V.E., CAVALCANTI, I.F.A., GAN, M.A., 1983. Contrasts between wet an dry periods within the 1981 rainy season in Northeast Brazil. INPE - 2728 PRE/310.

LOMBARDO, M. A. Ilha de calor nas metrópoles: o exemplo de São Paulo, São Paulo-SP: Editora Hucitec, 1985. 244p.

MCCULLOUGH, B.D.; HEISER, D. A. On the accuracy of statistical procedures in Microsoft Excel 2007, Computational Statistics and Data Analysis, 52, 45704578. 2008.

MOREIRA, C. M. Estratégias de simulação em supermercados: avaliação por meio de simulação. 2001. 148 f. Dissertação (Mestrado em Engenharia de Produção) - Universidade Federal de Santa Catarina, Florianópolis, 2001.

MORETTIN, P. A., TOLOI, C. M. C. Análise de séries temporais. São Paulo: Edgard Blücher, 2004. 535p.

MOURA, B A G; ARAGÃO, J O R; LACERDA, F F; PASSAVANTE, J Z O. Relação entre a Precipitação no setor leste do Nordeste do Brasil e a temperatura de superfície nos Oceanos Atlântico (área do dipolo) e Pacífico. Revista Brasileira de Engenharia Agrícola e Ambiental, v.4, n.2, p.247 - 251. 2000.

MUNN, R.E. Descriptive Micrometeorology. Advances in Geophysics. New York: Academic Press, 1996, v. I. 199p. 
SILVA, F D S; CORREIA, M F; ARAGÃO, M R S; SILVA, J M. Convecção linearmente organizada na área de Petrolina, semi-árido do Nordeste do Brasil: aspectos em meso e grande escala. Ver. Brás. Meteorol. Vol.23, n³. São Paulo. 2008.

TSONIS, E. S.; Elsner, T. K. Chaos, strage atractors and weather. Bulletin of the American Meteorological Society, Vol. 70, pg 14-23, 1999.

UVO, C. B.; REPELLI, C. A.; ZEBIAK, S. E.; KUSHNIR, Y. The Relationships between Tropical Pacific and Atlantic SST and Northeast Brazil Monthly Precipitation. J. Climate, 11, 551-562. 1998. 